\title{
Transradial intervention as the first choice of treatment for ST elevation myocardial infarction patients: editorial comment
}

Byoung Kwon Lee

Department of Internal Medicine, Yonsei University College of Medicine, Seoul, Korea
Received: June 14, 2018 Accepted: June 20, 2018

\section{Correspondence to} Byoung Kwon Lee, M.D. Department of Internal Medicine, Cardiovascular Center, Gangnam Severance Hospital, Yonsei University College of Medicine, 211 Eonju-ro, Gangnam-gu, Seoul o6273, Korea

Tel: +82-2-2019-3307

Fax: +82-2-3463-3882

E-mail: cardiobk@yuhs.ac

\section{See Article on Page 716-726}

Recently, transradial intervention (TRI) has been widely used for percutaneous coronary intervention (PCI). Over the past decades, TRI has become very efficacious even during complex procedures, given the remarkable advances in interventional devices. ST elevation myocardial infarction (STEMI) is highly thrombotic, associated with a high bleeding risk if antiplatelet and anticoagulation agents are given; bleeding complications compromise clinical outcomes. Several studies have demonstrated the efficacy and safety of TRI compared to transfemoral intervention (TFI) in STEMI patients [1-4]. These studies include the Radial Versus Femoral Access for Coronary Angiography or Intervention (RIVAL) study, the ST-Segment Elevation Myocardial Infarction Treated by Radial or Femoral Approach in a Multicenter Randomized Clinical (STEMI-RADIAL) trial, and the Radial versus Femoral Randomized Investigation in ST-segment Elevation Acute Coronary Syndrome (RIFLE-STEACS) study. All reported significant reductions in access site-related complications, lower mortality, and fewer net clinical adverse events (NACE) in acute coronary syndrome (ACS) patients in- cluding STEMI patients, attributable principally to significant reductions in bleeding and all-cause mortality. The Minimizing Adverse Haemorrhagic Events by TRansradial Access Site and Systemic Implementation of AngioX (MATRIX) trial confirmed that TRI improved outcomes compared to TFI, affording consistent benefits across the entire spectrum of ACS patients including STEMI patients [4]. A 2018 meta-analysis of 31 studies reported in the Cochrane database [5] found that TRI reduced 30-day short-term NACE, cardiac death, all-cause mortality, bleeding, and access site complications; but insufficient evidence was available in terms of long-term clinical outcomes.

In the current issue, Li et al. [6] describe the outcomes of TRI, including relatively long-term NACE, in STEMI patients. TRI for STEMI patients undergoing primary PCI featuring drug-eluting stents was associated with lower incidences of access site hematoma, 12-month repeat revascularization, and NACE compared to TFI, as has been found in previous studies. Interestingly, the repeat revascularization rate was significantly lower in the TRI group. The authors consider that this is explained by the complex lesional subset; complex patients might 
not be adequately handled in statistical terms because data were not randomized. Also, image-guided PCI was more frequent in the T'RI group. This finding should be confirmed in a large-scale, long-term, prospective randomized study. No significant differences in the revascularization rates associated with either approach were apparent in previous short-term studies.

Additionally, upon subgroup analysis of MATRIX data, the effects of radial versus femoral access were consistent across most subgroups including those defined by age, sex, body mass index, planned or actual prescription of prasugrel or ticagrelor versus clopidogrel, diabetes status, renal function, or a history of peripheral vascular disease. However, TRI afforded significantly better outcomes in high-volume centers (where over $80 \%$ of patients underwent TRI) [4], but TRI was associated with more operator and patient radiation exposure [7].

Conclusively, the evidence (including the findings of this study) suggests that TRI should be the first-line approach for patients, including STEMI patients who are hemodynamically stable, especially in high-volume TRI centers, with care taken to provide appropriate radiation shielding.

\section{Conflict of interest}

No potential conflict of interest relevant to this article was reported.

\section{REFERENCES}

1. Jolly SS, Yusuf S, Cairns J, et al. Radial versus femoral access for coronary angiography and intervention in patients with acute coronary syndromes (RIVAL): a randomised, parallel group, multicentre trial. Lancet 2011;377:1409-1420.

2. Romagnoli E, Biondi-Zoccai G, Sciahbasi A, et al. Radial versus femoral randomized investigation in ST-segment elevation acute coronary syndrome: the RIFLE-STEACS (Radial Versus Femoral Randomized Investigation in ST-Elevation Acute Coronary Syndrome) study. J Am Coll Cardiol 2012;60:2481-2489.

3. Bernat I, Horak D, Stasek J, et al. ST-segment elevation myocardial infarction treated by radial or femoral approach in a multicenter randomized clinical trial: the STEMI-RADIAL trial. J Am Coll Cardiol 2014;63:964-972.

4. Vranckx P, Frigoli E, Rothenbuhler M, et al. Radial versus femoral access in patients with acute coronary syndromes with or without ST-segment elevation. Eur Heart J 2017;38:1069-1080.

5. Kolkailah AA, Alreshq RS, Muhammed AM, Zahran ME, Anas El-Wegoud M, Nabhan AF. Transradial versus transfemoral approach for diagnostic coronary angiography and percutaneous coronary intervention in people with coronary artery disease. Cochrane Database Syst Rev 2018;4:CDo12318.

6. Li H, Rha SW, Choi BG, et al. Transradial versus transfemoral intervention in ST-segment elevation myocardial infarction patients in Korean population. Korean J Intern Med 2018;33:716-726.

7. Sciahbasi A, Frigoli E, Sarandrea A, et al. Radiation exposure and vascular access in acute coronary syndromes: the RAD-matrix trial. J Am Coll Cardiol 2017;69:2530-2537. 